УДК 81'362

DOI: 10.12731/2077-1770-2017-4-312-333

\title{
ЧАСТНЫЕ ВИДОВЫЕ ЗНАЧЕНИЯ РУССКОГО ГЛАГОЛА В ЗЕРКАЛЕ ВЬЕТНАМСКОГО ЯЗЫКА (НА МАТЕРИАЛЕ ПЕРЕВОДА «МЕРТВЫХ ДУШ» Н.В. ГОГОЛЯ)
}

\section{Ташлыкова М. Б., Буй Тху Хa}

Проблема передачи семантических нюансов русских видовых форм на другой язык возникает не только тогда, когда язык перевода не имеет соответствующей грамматической категории, но и тогда, когда такая категория есть, однако и способ ее организации, и содержание видовых противопоставлений имеют специифику, - как в случае с вьетнамским языком. В ходе предшествующего исследования был выявлен основной репертуар средств репрезентации частных видовых значений русского глагола во вьетнамском языке. Цель статьи - выявить закономерности использования таких средств при переводе «Мертвых душ» Н.В. Гоголя. Это задача решается в связи с проблемой более общего характера, а именно проблемой оченки степени адекватности перевода оригиналу, осмыслением тех находок и потерь, которые неизбежно сопровождают перевод. В результате исследования установлено, что максимальной близостью к оригиналу отличаются те фрагменты произведения, в которых аспектуальная семантика глагольной формы поддержана значениями единиц контекста (далее эти контексты характеризуются как «сильные»). Последние являются тем лексическим ресурсом, который облегчает переводчику его задачу. В тех случаях, когда такие единииь отсутствуют («слабые»контексты), возникает необходимость поиска специфических средств вьетнамского языка, способных передать характеристики описываемой ситуации. Иногда необходимые грамматические и/или лексические средства отсутствуют, и определеннье оттенки смысла остаются невыраженными. 
Область применения результатов. Результаты исследования могут быть использованы для уточнения ряда вопросов современной аспектологической теории: частные значения видов и методы их описания, роль контекста в репрезентации видовой семантики, художественный потенциал различных видовых форм, возможности передачи аспектуальных значений русского глагола в языке иной типологической разновидности, чем русский.

Ключевые слова: аспект; вид глагола; типологические исследования; русский язык; вьетнамский язык; перевод.

\section{SPECIAL ASPECT MEANINGS OF THE RUSSIAN VERB IN THE VIETNAMESE LANGUAGE CONTEXT (BASED ON THE TRANSLATION OF DEAD SOULS BY N. GOGOL)}

\section{Tashlykova M. B., Bui Thu Ha}

The problem of rendering semantic nuances of Russian aspect forms in another language appears not only when the translation language has no matching grammar category, but also when such categories exist but their structure and the meaning of aspect oppositions have their own peculiarities. It is true about the Vietnamese language. In the course of our previous research, we explored the way special aspect meanings of the Russian verb are represented in Vietnamese. We studied the basic means of such representation. The aim of this article is to find out the regular occurrence of such means while translating Dead Souls by N. Gogol. The task needs solving because there is another problem, the one being more common. We imply the problem of translation adequacy evaluation and the understanding of findings and losses caused by translation.

As a result of our research we have found out that certain fragments of the translation are more adjacent to the original. These are the fragments in which aspect semantics of the verb form is supported by the context (we call these contexts "strong"). This lexical tool makes the translator's task easier. In case such units are absent (i.e. "weak" contexts), the translator has to look for some specific means of the Vietnamese lan- 
guage which are able to describe the situation properly. Sometimes we fail to find necessary grammar and/or lexical means. In this case, some shades of the original meaning are left unexpressed.

Practical implications. The results of the study may be used to specify a number of issues of the contemporary aspectual theory, namely the special aspectual meanings and their description methods, importance of the context in the representation of aspectual semantics, possibilities of the Russian verbs' aspectual meanings representation in a language of a different typological system.

Keywords: aspect; verb aspect; typological research; Russian; Vietnamese; translation.

\section{0. Вводные замечания}

\section{1. Постановка задачи}

Сложность и уникальность русской категории вида, специфическое взаимодействие вида и времени, разнообразие частных видовых значений являют собой вызов для переводчика- особенно в тех случаях, когда язык перевода относится не к той типологической разновидности, к которой принадлежит язык оригинала.

В ходе предшествующего исследования мы выявили основные средства репрезентации частных видовых значений русского глагола во вьетнамском языке [4], [5], [6]. Цель настоящей работы - представить некоторые закономерности использования таких средств при переводе конкретного художественного произведения. Это задача решается в связи с проблемой более общего характера, а именно - проблемой оценки степени адекватности перевода оригиналу, осмыслением тех находок и потерь, которые неизбежно сопровождают перевод.

\section{2. Метод анализа}

Категория вида в статье понимается в соответствии с традицией интерпретировать аспектуальные категории как такие, которые определяют ситуацию с точки зрения особенностей ее разворачивания во времени, ее внутренней динамики, как «внутреннее вре- 
мя глагола» [1], [7], [11]. Частные видовые значения, как пишет А.В. Бондарко, представляют собой конкретную реализацию видового семантического потенциала [2, с. 19].

Как показывает анализ различных подходов к выявлению и определению частных видовых значений (см., например, работы Н.С. Авиловой, А.В. Бондарко, Ю.С. Маслова, Е.В. Падучевой, Анны А. Зализняк и А.Д. Шмелева, М.А. Шелякина), имеющиеся в лингвистической литературе классификации существенно отличаются не только по набору таких значений, но и по их содержательной интерпретации. Абсолютное совпадение точек зрения обнаруживается очень редко - при том, что во многих случаях наблюдается абсолютное расхождение. Ситуацию осложняет также тот факт, что однотипные употребления зачастую получают различную терминологическую квалификацию, и, наоборот, один и тот же термин у разных авторов наполняется разным содержанием. Более того, в силу разнообразия факторов и множественности оснований для выделения частных видовых значений, границы между ними зыбки, а их состав и количество неопределенны. Иерархические отношения между значениями в разных источниках также определяются по-разному.

Чтобы упорядочить разнообразие подходов и ликвидировать различие в количественной и качественной интерпретации частных видовых значений русского глагола, в работе предлагается описывать значения видо-временных форм через наборы аспектуальных и темпоральных семантических признаков. Так, например, актуальное настоящее характеризуется объединением следующих признаков: ('+ процессность', ‘+ конкретность', ‘+ временная локализованность действия’) + '+ одновременность (по отношению к грамматической точке отсчета)'. Такой же набор аспектуальных признаков в сочетании с темпоральным признаком '+ предшествование (по отношению к грамматической точке отсчета)' характеризует значение прошедшего несовершенного конкретного единичного действия. Подобным образом могут быть охарактеризованы другие частные видовые значения.

Опора на выделенные в исследовании наборы семантических признаков делает работу над эмпирическим материалом более эф- 
фективной, подчиняя ее единому алгоритму: определение частного видового значения осуществляется через выявление контекстуальных (лексических и грамматических) или ситуативных элементов, проясняющих наличие / отсутствие того или иного семантического компонента в составе глагольной граммемы.

\section{1. Перевод видовых форм \\ в составе «сильного» контекста}

Максимальной близостью к оригиналу отличаются те фрагменты вьетнамской версии «Мертвых душ», в которых аспектуальная семантика глагольной формы поддержана значениями единиц контекста (для удобства анализа будем далее характеризовать эти контексты как «сильные»). Последние являются тем лексическим ресурсом, который облегчает переводчику его задачу: в переводе используются вьетнамские языковые средства с тем же лексическим значением - либо сами по себе, либо с дополнительными видо-временными показателями.

\section{1. Способы выражения \\ семантического элемента '+ процессность'}

Семантический элемент '十 процессность', характеризируя конкретное процессное значение, эксплицитно выражается разного рода обстоятельственными индикаторами, способными к указанию на продолжительность действия. В следующих контекстах в роли таких индикаторов и в русском, и во вьетнамском языках функционируют слова и выражения минуты две - trong khoảng hai phút, постоянно - vẫn, два года - hai пӑm, около года - một năm, целую зиму - suốt môt mùa đông (Далее используется специальная система обозначений, где - маркер, который указывает на оригинальный, а не переводной текст, О - дословный перевод, $\bullet$ - литературный перевод. Оригинальный текст и литературный перевод выделяются курсивом, дословный - с помощью марровских кавычек).

* В его кабинете всегда лежала какая-то книжка, заложенная закладкою на четырнадизатой странице, которую он п्стоянно читал уюе два года. 
- Trong buồng làm việc, chàng giũ cuốn sách có cái chắn đánh dấu trang 14 mà chàng vẫn đoc dơ tù̀ hai năm nay.

О 'в кабинет он держать книга иметь закладка на страница четырнадцатый который он все еше читать два год’

В качестве показателя длительности используются слова типа всё, всё ещце, всё время (không ngót mồm, vẫn còn, suốt buổi) которые акцентируют мысль о том, что действие, описываемое в следующих фрагментах глагольными формами усмехался, пищит, смеется, продолжается и неизвестно, когда оно закончится:

Одни тоненькие ... всё увивались около дам.

- Hạng gày thì ... suốt buối theo tán tỉnh phái đẹp.

○ 'тоненький все время увиться около дама'

Наряду с теми лексическими средствами, которые актуализируют значение процессности, в большом количестве случаев используются специализированные показатели длительности (dang, còn), cp.:

* И потом (Чичиков) ещзе долго сидел в бричке, придумывая, кому бы ещче отдать визит.

- Sau đó, ngồi trong xe, y $\underline{\text { còn }}$ nghĩ mãi hồi lâu xem còn ai có thể đến thăm nũa không.

○ ‘потом сидеть в бричка он все еще придумать показатель длительности долго кто отдавать визит'

В приведенном примере наречие долго и выражение в это время, сохраненные в переводе, сами по себе обеспечивают возможность восприятия ситуации как продолжающейся. Однако переводчик не ограничивается этими ресурсами и добавляет видо-временной показатель đang в первом случае, и слово $\boldsymbol{m} \tilde{a} \boldsymbol{i}-$ во втором, причем добавляет специально - для того чтобы подчеркнуть признак длительности глагольного действия.

\section{2. Способы выражения \\ семантического компонента '+ кратность'}

Кратность воплощается в переводе на вьетнамский язык с помощью различных темпоральных маркеров и устойчивых конструкций. 
В следующем контексте значение кратности глагольного действия говорить выражается с помощью наречия thừ̀ng 'обыкновенно':

* «Да, шаловлив, шаловлив, - говорил обыкновенно на это отеи.

- «Vâng, nó nóng nảy, nóng nảy lắm», ông bố thường đáp lai thế.

$\bigcirc$ 'да он шаловливый шаловливый очень отец обыкновенно говорить на этот так’

Значения наречий и наречных выражений могут поддерживаться с помощью специальных показателей:

(Губернатор), впрочем, был большой добряк и даже сам $\underline{\text { вы- }}$ шивал иногда по тюлю.

- Nhung vốn ngài là một người hiền tù̀, dôi khi lại còn thích tụ tay thêu thùa lên vải tuyn nũa kia.

О 'впрочем он быть добряк иногда показатель кратности сам вышить по тюль'

Значение неограниченной кратности воплощается в переводе на вьетнамский язык в устойчивых конструкциях lúc nào cũng 'беспрестанно + cũng', bao giờ cũng 'непременно + cũng'. Наличие слова $\boldsymbol{c} \tilde{\boldsymbol{u n g}}$ в составе этих устойчивых конструкций является обязательным. Его употребление в таких случаях вытекает не из желания переводчика, а из закономерностей устройства данного фрагмента лексики во вьетнамском языке.

* Ни на одном собрании, где он был, не обходилось без истории. Какая-нибудь история непременно происходила.

- Bất kỳ đâu mà có hắn, là bao giờ cũng có việc gì đấy xảy ra cho hắn.

$\bigcirc$ 'везде где он есть непременно показатель кратности произойти какой-н история'

\section{3. Способы выражения семантического оттенка '+ постоянность свойства'}

Как показал анализ материала, значение постоянного отношения, для которого характерна максимальная временная локализация и неограниченная длительность, реализуется с помощью разнообразных средств контекстуальной поддержки. 
К числу таких средств относятся в первую очередь сравнения и различные лексические и грамматические показатели обобщенности. В переводе (разумеется, с поправкой на специфику вьетнамского языка) сохраняются и те, и другие.

Типизация - главная отличительная черта гоголевской манеры повествования - наиболее эксплицитно представлена в контекстах, содержащих сравнительные конструкции. Рассмотрим некоторые из них.

Некоторые из них были такого рода, что с трудом можно было отличить их от петербургских, имели мак жее весьма обдуманно и со вкусом зачесанные бакенбарды или просто благовидные, весьма гладко выбритые оваль лии ... .

- Vài người trong bon ho thật khó mà phân biệt được với các công tử ở Pêterbua; cũng nhu bon ấv, họ chải bộ râu má rất diêm dúa, hay phô ra nhũng bộ mặt trái xoan cạo nhã̃n thín..

$\bigcirc$ ' показатель мч некоторый из показатель мч они трудно отличиться ${ }^{\text {показа- }}$ тель Мч от показатель мч петербурский как они они так же зачесать бакенбарды обдуманно или показать показатль мч лицо овальный бриться'

Наличие слов типа cũng nhu bọn ho 'такие же, как они', cũng thế 'так же' акцентирует внимание на том, что предмет речи включается в широкий ряд своих подобий. В условиях данного аспектуального контекста глагол деятельности сó 'иметь' тяготеет к выражению значения экзистенциальности и постоянного отношения.

Те фрагменты текста, в которых отражена установка автора на типизацию (описание тех или иных ситуаций в рамках субъектного, временного и пространственного обобщения), сохраняют в переводе все контекстуальные элементы, воплощающие эту установку - обобщенные субъекты, обобщенные темпоральные и локативные показатели.

Так, например, в следующем контексте наличие словосочетания, называющего обобщенное место (в губернских городаx $\rightarrow$ các tỉnh $\boldsymbol{l y}$ ), позволяет читателю понять, что ситуация описывается в широком плане настоящего:

Покой известного рода, ибо гостиница тоже известного рода, то есть именно такая, как бывают гостиницы в губернских zopodax. 
- Căn phòng ấy chẳng có gì là đặc biệt cả; nghĩa là giống hệt moi khách sạn ở các tỉnh ly.

О 'этот гостиница не особенный, то есть похожий на артикль непред. гостиница в артикль неорел. губернский город’

В некоторых фрагментах дополнительно вводится наречие thường 'обычно', что дает возможность максимально точно передать атемпоральное значение, реализуемое в этих фрагментах оригинального текста видо-временными формами настоящего НCB: действие предстает не как происходящее в конкретный момент на оси времени, а как неограниченно длительное, максимально широко локализованное во времени.

В ворота гостинииы губернского города NN въехала довольно красивая рессорная небольшая бричка, в какой ездят холостяки.

- Cỗ xe ngựa tiến vào cổng một khách sạn ở tỉnh ly N.N. đó là một chiếc xe Britska nhỏ, khá đẹp, có díp, kiểu xe mà nhũng kẻ đôc thân thường dùng.

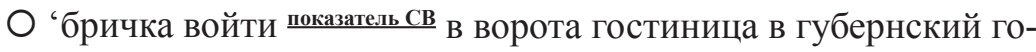
род NN это бричка небольшой довольно красивый рессорный в который показалел Мч холостяк обычно ездить'

В целом ряде контекстов, содержащих показатели субъектного обобщения, наряду с именами типичных субъектов (русский $\rightarrow$ ngưòi nga, толстые $\rightarrow$ hạng béo ', тоненькие $\rightarrow$ hạng gày) используются определительные местоимения khách, hạng, ngưòi 'всякий, каждый, любой, неизвестно какой, разный, всевозможный' . Эти местоимения способствуют выражению идеи обобщенности субъекта, обладающего характерными свойствами, нелокализованными во времени.

* И какой же русский не любит быстрой езды?

- Vả lai ngưòi Nga nào mà chắng thích đi nhanh?

О 'и каждый русский кто не любить быстрый езда'

В данных ситуациях в переводе полностью сохраняется значение настоящего вневременного, несмотря на то что сама глагольная форма не передает это значение.

Итак, в составе «сильных» контекстов важнейшие компоненты аспектуальности - процессность, кратность, нелокализованность 
глагольного действия во времени полностью сохраняются в переводе благодаря окружению.

Специализированные видовые и невидовые показатели функционируют в таких контекстах как дополнительное средство, позволяющее вьетнамскому читателю максимально точно воспринять аспектуальные характеристики описываемой ситуации.

Использование специализированных показателей в «сильных» контекстах подчиняется определенной тенденции: они употребляются главным образом в тех фрагментах, в которых глагольные формы реализуют имперфектное значение, характеризуемое семантическими элементами процессности и кратности.

Таким образом, сохранение детерминантных и обстоятельственных элементов оригинального текста обеспечивает возможность адекватного перевода, а использование видовых показателей является своего рода актуализатором определенных компонентов видового значения.

\section{2. Перевод видовых форм в составе «слабого» контекста}

Передача частных видовых и видо-временных значений в переводе на вьетнамский язык представляется наиболее сложной в таких случаях, в которых оригинальный текст не содержит средств контекстуальной поддержки аспектуальных особенностей глагола. В таких случаях переводчику требуются дополнительные лексические и грамматические ресурсы, позволяющие указать на характер описываемого действия. Используемые показатели могут быть видовыми или невидовыми, но способными выражать то или иное аспектуальное значение.

Как показывает анализ, специализированные показатели оказываются необходимыми главным образом для тех фрагментов, которые организованы глаголами СВ.

\section{1. Перевод форм СВ в составе «слабого» контекста 2.1.1. Способы выражения семантического признака '+ целостность'}

Из 1634 рассмотренных глагольных форм, извлеченных методом сплошной выборки из анализируемых фрагментов, 613 являются 
формами СВ. 571 из них выражает конкретно-фактическое значение, основным семантическим компонентом которого является '十 целостность'.

В переводе на вьетнамский язык этот параметр часто передается с помощью видовых показателей được, ra, rồi, thấy, mất, đi, hết, hẳn, xong, lên. Именно они указывают на ограниченность действия пределом, т. е. на его целостность.

Такое действие может размещаться на разных участках временно́й оси.

Рассмотрим вначале те примеры, в которых законченность описываемого действия фиксируется в определенном моменте в прошлом.

* Вельможа тотчас его узнал.

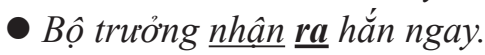

$\bigcirc$ 'вельможа узнать показатель св он сразу'

Значение целостности завершившегося действия выражается более ярко благодаря наличию в одном контексте сразу нескольких видовых уточнителей. Ср.:

* Эx, тройка! птииа тройка, кто тебя вылумал?

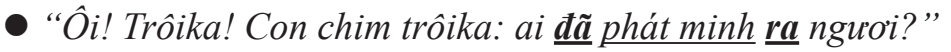

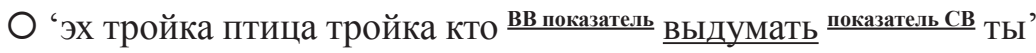

Использование нескольких показателей наблюдается и в тех случаях, когда имеющийся в контексте обстоятельственный компонент не связывается однозначно с семантикой вида:

Еще третью неделю взнесла больше полутораста. Да заседателя подмаслила.

Cách đây mười lăm ngàv, tôi phải đóng hơn một trăm năm muơi rúp! Thế mà đãa phải đấm mõm cho ông trợ tá rồi đấy.

○ 'пятнадцать день назад я должен внести больше полутораста да $\underline{\text { вВ показатель }} \underline{\text { подмаслить заседатель показатель СB }}$,

Словосочетание третью неделю и последние три года допускают сочетаемость с формами НСВ (ср. третью неделю продолжается спор, последние три года свирепствовала горячка), поэтому для выражения семантического признака целостности, характери- 
зующего формы взнесла, подмаслила, выморила, переводчик употребляет аспектуальные частицы $\boldsymbol{d} \tilde{a}, \boldsymbol{r o ̂ ̀ i}$, которые в полной мере передают идею завершенности действия.

\subsection{2. Способы выражения семантических комплексов}

'+ целостность' '+ наличная результативность'

Сочетание семантических параметров '+ целостность' '+ наличная результативность', характерное для перфектного значения русского глагола СВ (в тексте это значение реализуют 33 глагольные словоформы), отображается во вьетнамском тексте с помощью нескольких показателей.

Это, во-первых, послелоги hết, lên, đi, mất.

Так, в следующем контексте идея наличного результата - утраты при завершении действия (умирание крестьян) - выражается видовым показателем-послеслогом hết:

Сколько у нас умерло крестьян с тех пор, как подавали ревизию?

- Tù là̀n điều tra dân số vù̀a rồi đến nay, ta mất hết bao nhiêu nông dân?

О 'с тех пор пока подавать ревизия у нас умереть показатель Св сколько крестьянин'

\subsection{3. Способы выражения}

семантических комплексов '十 целостность' '+ следствие (по отношению к грамматической точке отсчета)'

Глаголы СВ широко используются для обозначения действия, которое произойдет после момента речи или какой-нибудь другой точки отсчета. Для таких употреблений также характерен компонент '+ целостность', однако, ситуация принадлежит будущему времени. В выражении значения совершенного вида играют роль уже упомянутые показатели được, ra, rồi, thấy, mất, đi, hết, hẳn, xong, lên.

Они могут однозначно сигнализировать об отнесенности действия к плану будущего даже в отсутствие временны́х маркеров. Ср.: 
B один год так ее наполнят всяким бабьем, что сам родной отеи не узнает.

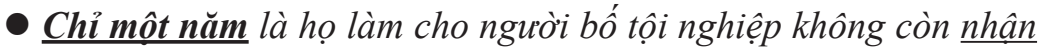
ra con gái nũa.

О 'только через один год бедный отец не узнать показатель Св дочь'

Обстоятельственное выражение в один год задает промежуток времени, в котором может осуществиться действие. Однако этот промежуток способен располагаться на разных участках темпоральной шкалы, ср. в один год наполнят - в один год наполнили. Вероятно, именно поэтому переводчик выбирает более однозначный вариант контекстуального показателя - chi môt năm ('только через один год’), а также использует видовой маркер $\boldsymbol{r a}$, который акцентирует идею возможности достижения результата действия узнавать в будущем.

В некоторых случаях специализированные маркеры совмещают две функции - указания на аспектуальность и указания на модальность:

Так, в следующем примере благодаря слову đươ'c эксплицитно выражается значение целостности обозначаемого факта и подчеркивается оттенок возможности или невозможности осуществления действия.

* Beдь это деньги. Bы их не cbluете на улицее.

- Số tiền có nhỏ đâu! Có phải cú ra ngoài đuoơng là nhăt được đâu.

○ 'это немалый сумма деньги не может быть что на улица искать показатель Св,

Как представляется, ориентация на поиск таких средств, которые сделают мысль автора максимально ясной для вьетнамского читателя, весьма характерна для анализируемого перевода. Именно этой ориентацией можно объяснить включение в следующий фрагмент текста не только видовых маркеров типа $\boldsymbol{r a}$, но и дополнительных лексических элементов.

Мы с Павлом Ивановичем скинем фраки, маленько приотдоxнем!

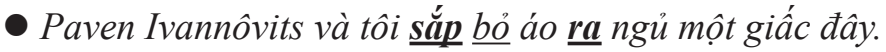

О 'Павел Иванович и я сккоро скинуть фрак показатель св спать' 
Наречие sắp сообщает о том, что действие скинуть фраки совершится в близком, непродолжительном будущем. В переводе данного предложения не упоминается действие приотдохнуть: $\mathbf{M b l ~ c}$ Павлом Ивановичем скоро скинем фраки чтобы поспать.

Самым частотным показателем отнесенности действия к плану будущего является частица $\boldsymbol{s} \tilde{\boldsymbol{e}}$ (ее содержат 45 контекстов из 181), которая употребляется и сама по себе, и в сочетании с другими средствами.

Так, использование временного показателя $\boldsymbol{s} \tilde{\boldsymbol{e}}$ и видового показателя đươ в следующем примере обеспечивают точность интерпретации глагола kiếm как обозначения целостного действия, осуществляемого после момента речи:

Когда генерал говорит, чтобы я поискал сам средств помочь себе, - хорошо, говорит, я, говорит, найдусредства!

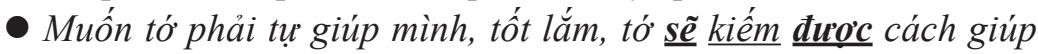
lấy minh.

$\bigcirc$ 'хотеть я должен сам помочь себя хорошо я $\underline{\text { вв показатель }} \underline{\text { найти }}$ показатель СВ средство помочь себя'

В некоторых местах для усиления модального оттенка добавляются наречия chắc chắn 'обязательно' и sắp ‘скоро'. Слово sẽ остается простым сигналом будущего времени. Ср.:

* Самая полнота и средние лета Чичикова много повредят ему ... весьма многие дамы, отворотивиись, скажут: "Фи, такой гадкий!»

- Vóc người phì nộn với cái tuổi trung niên của Tsitsikôp chắc chắn

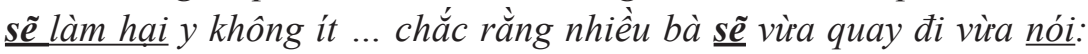
«Eo! Xấu khiếp!»

О 'полнота и средний год у Чичиков обязательно показатель БВ дить он немало обязательно многий дама показатель Бв и отворотиться и говорить фи такой гадкий'

С помощью наречия chắc chắn выражается оценка действий noвредить и сказать как безусловных, непременных для исполнения.

Как видно из приведенных в данной части работы примеров, в абсолютном большинстве случаев русские формы СВ не требуют 
контекстуальной поддержки, потому что имеют внутрисловные маркеры аспектуальности - главным образом префиксы (см. перечень рассмотренных форм: узнал, вылумал, вылла, взнесла, подмаслил, умерло; напишете, узнает, доедет, сыщете, выдумает, приотдохнем, скинем, найду, повредят). Формы НСВ легко обходятся безо всяких показателей (за исключением суффиксов имперфективации) и тем самым дополнительно усложняют переводчику его работу.

\section{2. Перевод форм НСВ в составе «слабого» контекста}

Формы НСВ, как уже отмечалось, довольно редко используются во фрагментах, не содержащих средств контекстуальной поддержки видового значения. В ходе анализа обнаружилось только несколько фрагментов такого рода. Интересно при этом, что семантический параметр ‘+ процессность’ реализуется в единичных случаях.

Показательно, что в контекстах с НСВ широко используются синонимические средства выражения этого значения, такие как $\boldsymbol{c} u$, còn, vẫn còn (всё ещце). Они позволяют передать представление о длительности действия или состояния и / или сохранении состояния в момент речи.

На это, в частности, указывает элемент cút при глаголе tưởng (дyмать), акцентирующий мысль автора о том, что говорящий имел об адресате определенное мнение, которое было актуально до момента речи (и которое вот-вот изменится).

* Я думал было прежде, что ты хоть сколько-нибудь порядочный человек.

- Tớ cú tưởng cậu là người lịch sự.

○ 'я все еще думать что ты есть порядочный человек'

В следующих контекстах вышеупомянутые показатели сигнализируют о сохранении наличного состояния, причем в последнем случае на выражение этой идеи работает также дополнительно введенное переводчиком слово hiện 'сейчас':

Mы напишем, что они живы, так, как стоит действительно в ревизской сказке. 
- Chúng ta ghi rõ là chúng còn sống, như vẫn ghi trong tò̀ khai dân số.

○ 'мы писать что они живой так как все еще писать действительно в сказка ревизский'

Как правило, средства контекстуальной поддержки отсутствуют в тех случаях, в которых формы НСВ выражают потенциально-качественное значение или значение постоянного свойства. Переводчик компенсирует недостаток таких средств введением глагола biết 'уметь' или наречия thường 'часто', сочетания có là 'быть в наличии'. Сp.

- Такие вылили славные работницы: сами салфетки ткут.

- Hai đứa là thơ giỏi: chúng biết dêt cả khăn!

○ 'две быть славный работница они уметь ткать салфетка'

Лицо его (Плюшкина)... было почти такое же, как у многих худощавых стариков, один подбородок только выступал очень далеко вперед ...

- Mặt lão cũng nhu mặt của nhiều người già, gầy gò, không có gì đặc biệt; chỉ có cái cằm nhô ra quá múc ...

○ 'лицо он такой же как лицо у многий старик худой нет особенный только быть в наличии подбородок выступить очень далеко вперед'

Введенное автором в переводе последнего примера сочетание chi có 'быть в наличии, существовать' придает высказыванию следующий смысл: 'лицо его такое же, как у многих худощавых стариков, только подбородок у него есть (существует) выступающий очень далеко вперед'. Таким образом, описываемая черта персонажа (выступающий подбородок) понимается как характерная для него. Оттенок постоянного отношения у глагола выстуnаmb, peaлизуемый в данном высказывании, в целом сохранен.

Итак, в «слабых» контекстах преобладают формы СВ, которые в русском оригинале эксплицитно (с помощью внутрисловных показателей) выражают значения, в основе которых лежат семантические признаки целостности и наличной результативности. Формы НСВ встречаются редко, они реализуют, как правило, значение постоянного отношения. Случаи употребления НСВ в «слабых» 
контекстах для передачи признака процессности не поддаются типизации.

При репрезентации частных видовых значений, реализуемых в «слабых» контекстах, переводчику необходимо подобрать все имеющиеся во вьетнамском языке средства (собственно видовые и видо-временные показатели, временные маркеры, передающие различные оттенки грамматического значения вида, лексические элементы), для того чтобы с максимальной точностью выразить аспектуальную характеристику каждого описываемого действия и избежать неоднозначного понимания ситуации или искажения исходного смысла предложения.

В ряде случаев, как уже отмечалось, аспектуальные параметры глагольной словоформы маркируются внутрисловными показателями (префиксами или суффиксами). Эти маркеры, средства языка синтетического строя, в переводе на вьетнамский язык последовательно заменяются аналитическими аналогами. Важно подчеркнуть, что видовые и видо-временные показатели, используемые в «сильных» и «слабых» контекстах, могут формально совпадать, различаясь при этом своей функциональной направленностью: в первых они выполняют актуализирующую, акцентирующую роль, а во вторых являются главным средством репрезентации видового значения.

Следует отметить, что точный перевод русских видовых форм в составе «слабых» контекстов оказывается возможным далеко не всегда. К числу особенно сложных проблем репрезентации видовой семантики русского глагола в художественном переводе «Мертвых душ» на вьетнамский язык можно отнести проблемы передачи конкуренции видов (см. об этом [5]), наглядно-примерного значения СВ и значения настоящего исторического. В таких случаях переводчик, будучи носителем языка иного типологического строя, чем русский, языка, воплощающего иную картину мира, не в силу уловить отдельные тонкости в употреблении видов и понять выбор автора. Анализ названных ситуаций составляет предмет самостоятельного исследования. 


\section{Выводы}

Исследование способов отражения семантики русского вида в художественном переводе поэмы Н.В. Гоголя «Мертвые души» на вьетнамский язык с неожиданной стороны показал специфику функционирования русских видовых форм: средства контекстуальной поддержки в абсолютном большинстве случаев сопровождают глаголы НСВ, СВ в таких средствах почти не нуждается; для реализации значений совершенного вида достаточно минимального контекста.

Это объясняется тем, что СВ, называя действие, достигшее своего внутреннего предела, является маркированным членом видового противопоставления. НСВ же, не обладая данным семантическим признаком, характеризуется как немаркированная форма. Именно поэтому его реализация всегда сопровождается большим количеством контекстуальных элементов, и по этой же причине переводить такие формы более просто - достаточно использовать аналогичные русским детерминантные и обстоятельственные группы. Иначе говоря, в таких случаях на переводчика работает «внешний» синтаксис (межсловные показатели, проясняющие аспектуальные характеристики глагольной словоформы).

При переводе форм СВ ориентиром могут служить средства «внутреннего» синтаксиса (внутрисловные показатели), которые сигнализируют о главных аспектуальных характеристиках СВ - целостности и предельности.

Вышеизложенное объясняет тот факт, что в составе «сильных» контекстов ведущую роль в репрезентации частных видовых значений играют единицы окружения. Специализированные видовые и невидовые показатели функционируют в таких контекстах в роли актуализаторов важнейших признаков видовых значений. В составе «слабых» контекстов эти же показатели являются главным выразителем аспектуальных характеристик.

Таким образом, передача аспектуальных значений русского глагола во вьетнамском языке обеспечивается наличием, с одной стороны, межъязыковых соответствий, с другой - специфических средств, 
которые позволяют преодолеть различие между синтетизмом, характерным для русского языка, и аналитизмом, присущим вьетнамскому.

Однако во многих случаях данное различие затрудняет поиск адекватного отражения значений видовых и видо-временных форм русского глагола во вьетнамском языке и передачу этих семантических тонкостей в переводе с одного языка на другой.

Подытоживая, подчеркнем, что применение оптики одного языка позволяет понять и переосмыслить нечто существенное в другом.

\section{Список литературы}

1. Аксаков К.С. О русских глаголах. М.: Тип. Л. Степановой, 1855. 47 с.

2. Бондарко А.В. Вид и время русского глагола: значение и употребление. М.: Просвещение, 1971. 239 с.

3. Бондарко А.В. Общие и частные значения грамматических форм: на материале категорий времени и вида в русском языке // Вопросы языкознания. 1968. № 4. С. 87-99.

4. Буй Т.Х. Значения видо-временной формы русского глагола и способы их выражения во вьетнамском языке // Современные исследования социальных проблем (электронный журнал). 2012. № 4. URL: http://sisp. nkras.ru/e-ru/issues/2012/4/bui.pdf (Дата обращения: 29.08.2017).

5. Буй Т.X. Конкуренция видов в русском нарративном тексте (проблема ее передачи на вьетнамский язык) // Филологические науки. Вопросы теории и практики. Тамбов: Изд-во «Грамота», 2014. № 6 (36). Часть 1. С. 37-39.

6. Буй Т.Х., Ташлыкова М.Б. Способы репрезентации частных видовых значений русского глагола во вьетнамском языке // Сибирский филологический журнал. 2014. № 4. С. 203-213.

7. Гловинская М.Я. Семантические типы видовых противопоставлений русского глагола. М.: Наука, 1982. 155 с.

8. Гловинская М.Я. Семантика, прагматика и стилистика видо-временных форм // Грамматические исследования. Функционально-стилистический аспект. 1989. С. 74-146.

9. Зализняк А.А., Шмелев А.Д. Введение в русскую аспектологию. М.: Языки русской культуры, 2000. 213 с. 
10. Маслов Ю.С. Вопросы глагольного вида в современном зарубежном языкознании // Вопросы глагольного вида. М.: Иностранная литература, 1962. С. 7-32.

11. Маслов Ю.С. Избранные труды: Аспектология. Общее языкознание. М.: Языки славянской культуры, 2004. 840 с.

12. Падучева, Е.В. Семантика вида и точка отсчета // Известия РАН. Серия литературы и языка. 1986. Т. 45. № 5. С. 413-424.

13. Падучева Е.А. Семантика времени и вида в русском языке. Семантика нарратива. М.: Языки русской культуры, 1996. 552 с.

14. Русская грамматика: В 2 т. Т. 1. Фонетика. Фонология. Ударение. Интонация. Введение в морфемику. Словообразование. Морфология. [Под ред. Н.Ю. Шведовой]. М.: Наука, 1980. 789 с.

15. Шелякин М.А. Категория аспектуальности русского глагола. М.: ЛКИ, 2008. 272 с.

\section{References}

1. Aksakov K.S. O russkikh glagolakh [Aspect and time of the Russian verb: meaning and use]. Moscow: Tip. L.Stepanovoy, 1855. $47 \mathrm{p}$.

2. Bondarko A.V. Vid i vremya russkogo glagola: znachenie $i$ upotreblenie [Aspect and time of the Russian verb: meaning and use]. Moscow: Prosveshchenie, 1971. $239 \mathrm{p}$.

3. Bondarko A.V. Obshchiye i chastnyye znacheniya grammaticheskikh form: na materiale kategoriy vremeni i vida v russkom yazyke [General and particular meanings of grammatical forms: on the material of categories of time and aspect in the Russian language]. Voprosy yazykoznaniya [Questions of linguistics]. 1968. № 4, pp. 87-99.

4. Bui T.H. Znacheniya vido-vremennoy formy russkogo glagola i sposoby ikh vyrazheniya vo v'yetnamskom yazyke [The meanings of the aspectual-temporal form of the Russian verb and the ways of their expression in Vietnamese]. Sovremennyye issledovaniya sotsial'nykh problem [Modern researchs of social problems]. 2012. № 4. URL: http://sisp.nkras.ru/e-ru/ issues/2012/4/bui.pdf.

5. Bui T.H. Konkurentsiya vidov v russkom narrativnom tekste (problema yeye peredachi na v'yetnamskiy yazyk) [The competition of aspectual forms in 
the Russian narrative text (the problem of its transmission in Vietnamese)]. Filologicheskiye nauki. Voprosy teorii i praktiki [Philological Sciences. Questions of theory and practice]. 2014. № 6 (36). Part 1, pp. 37-39.

6. Buy T.KH., Tashlykova M.B. Sposoby reprezentatsii chastnykh vidovykh znacheniy russkogo glagola vo v'yetnamskom yazyke ) [The ways of representation of particular aspectual meanings of the Russian verb in Vietnamese]. Sibirskiy filologicheskiy zhurnal [Siberian Philological Journal]. 2014. № 4, pp. 203-213.

7. Glovinskaya M.YA. Semanticheskiye tipy vidovykh protivopostavleniy russkogo glagola [Semantic types of aspectual oppositions of the Russian verb]. Moscow: Nauka, 1982. 155 p.

8. Glovinskaya M.YA. Semantika, pragmatika i stilistika vido-vremennykh form [Semantics, pragmatics and stylistics of the aspectual- temporal forms]. Grammaticheskiye issledovaniya. Funktsional'no-stilisticheskiy aspekt [Grammatical Studies. Functional-stylistic aspect]. 1989, pp. 74-146.

9. Zaliznyak A.A., Shmelev A.D. Vvedeniev russkuyu aspektologiyu [Introduction to Russian aspectology]. Moscow: Yazyki russkoy kul'tury, 2000. 213 p.

10. Maslov YU.S. Voprosy glagol'nogo vida v sovremennom zarubezhnom yazykoznanii [Questions of aspectual forms in modern foreign linguistics]. Voprosy glagol'nogo vida [About aspectual forms]. Moscow: Inostrannaya literatura,1962, pp. 7-32.

11. Maslov YU.S. Izbrannyye trudy: Aspektologiya. Obshcheye yazykoznaniye [Selected Works: Aspectology. General Linguistics]. Moscow: Yazyki slavyanskoy kul'tury, 2004. 840 p.

12. Paducheva E.A. Semantika vida i tochka otscheta [Semantics of the aspect and reference point]. Izvestiya RAN. Seriya literatury i yazyka [Proceedings of the Russian Academy of Sciences. A series of literature and language]. 1986. V. 45. № 5, pp. 413-424.

13. Paducheva E.A. Semantika vremeni $i$ vida v russkom yazyke [The semantics of time and aspect in russian. The semantics of the narrative]. Moscow: Yazyki russkoy kul’tury, 1996. 552 p.

14. Shvedova N.Yu. Russkaya grammatika [Russian grammar]: In 2 volumes. Vol. 1. Fonetika. Fonologiya. Udarenie. Intonatsiya. Vvedenie v morfemiku. Slovoobrazovanie. Morfologiya [Phonetics. Phonology. Ac- 
cent. Intonation. Introduction to morphemics. Derivation. Morphology]. M.: Nauka, 1980. 789 p.

15. Shelyakin M.A. Kategoriya aspektual'nosti russkogo glagola [The category of aspect of Russian verb]. Moscow: LKI, 2008. 272 p.

\section{ДАННЫЕ ОБ АВТОРАХ}

Ташлыкова Марина Борисовна, и.о. директора Института филологии, иностранных языков и медиакоммуникации, кандидат филологических наук, доцент

Иркутский государственный университет

ул. К.Маркса, 1, г. Иркутск, 664003, Российская Федераџия taschlykoff@mail.ru

SPIN-code: 3570-0673

Буй Ха Тху, преподаватель русского языка факультета русского языка и русской культуры института иностранных языков Институт иностранных языков при Ханойском государственном университете

ул. Фам Ван Донг, 1, Дич Вонг Хау, Кау-Гжай, Ханой, Вьетнам buithuha8887@gmail.com

\section{DATA ABOUT THE AUTHORS}

Tashlykova Marina Borisovna, Acting Director of the Institute of Philology, Foreign Languages and Media Communications, Ph.D., Associate Professor

Irkutsk State University

1, K.Marks Str., Irkutsk, Irkutskaya oblast', 664003, Russia taschlykoff@mail.ru

SPIN-code: 3570-0673

Bui Thu Ha, Lecturer, Department of Russian Language and Russian Culture University of Languages and International Studies, Hanoi State University

1, Pham Van Dong Str., Dich Vong Hau, Cau Giay, Hanoi, Vietnam buithuha8887@gmail.com 